\title{
Online Hierarchical Controller for Hybrid Power System
}

\author{
Salem Zerkaoui \\ Al Baha University, P.O. Box 1988, Al Baha 61008, Saudi Arabia \\ Correspondence should be addressed to Salem Zerkaoui, sazerkao@gmail.com
}

Received 5 September 2012; Accepted 23 September 2012

Academic Editors: B. Chen and A. Stoppato

Copyright (C) 2012 Salem Zerkaoui. This is an open access article distributed under the Creative Commons Attribution License, which permits unrestricted use, distribution, and reproduction in any medium, provided the original work is properly cited.

This paper presents the basis for the development of an intelligent and autonomous energy management strategy for hybrid power system (HPS). Two hierarchical levels are proposed to control and manage the HPS. The low level is performed by a local control unit (DC-DC converters controller) of the different power sources. Dynamic equations describing the coupling of converters are derived, and a robust sliding mode dynamic controller is designed. The high level is performed by the online supervisor unit. This unit is designed by applying on-line Takagi-Sugeno fuzzy logic principles. As a result the robust control system gets rid of the limits of the HPS, which has the imprecision, uncertainty, strong coupling, and nonlinearity, to achieve its tractability, robustness, and low solution cost. Under the operation constraints related to each type of sources, the simulation results show that the optimal operation objective of HPS has been achieved.

\section{Introduction}

The limited reserves of fuel oils, their pollution impact, and their unstable prices have significantly increased the interest in renewable energy sources (RES: photovoltaic modules, wind turbine, etc.) to produce electricity that is an essential factor for the development of the human societies. In this context, HPSs, which combine renewable energy and conventional energy sources with the storage systems, are very interesting in terms of environmental protection and reduction of the effects of greenhouse gas emissions. In other words, the HPSs can provide an economic, environment friendly, and reliable supply of electricity.

To perform the hybrid systems a control strategy has to be designed and implemented on the system. Numerous solution methodologies have been proposed in this field in the last decade [1-4]. Many of them are based on a static approach. However, the development of robust controller is necessary to ensure stability and robustness of the multisources of the renewable energy systems.

Subsequently, others advanced control strategies, such as predictive control, fuzzy logic, and neural network, have been developed and successfully applied [5-7]. However, these approaches require considerable computing resources and as a result their applicability for real-time applications is reduced.

In this paper, emphases are put on the energy management and control from the viewpoint of control theory. The proposed management strategy and controller, designed by applying fuzzy logic and sliding mode principles, not only is simple, stable, and robust, but also reduces the computational resources. Two hierarchical levels are required to control and manage the HPS. The low level is performed by a local control unit (DC-DC converters controller) of the different power sources. This level manipulates the duty cycle converter according to the variation of the sources and the load. Without the use of cascade structure commonly used in literatures, I proposed a robust control law based on sliding mode control approach to operate the DC-DC converters in the most efficient way.

The high level is performed by the online supervisor unit. This unit uses the data about the load, the meteorological conditions and the charge state of energy storage system (ESS) and combustion engine (CE), to correctly and efficiently share the load demand according to the availability of conventional and renewable energy, in other words, to decide whether to charge or discharge the ESS, to turn on or off the $\mathrm{CE}$, to reduce the renewable sources power production 


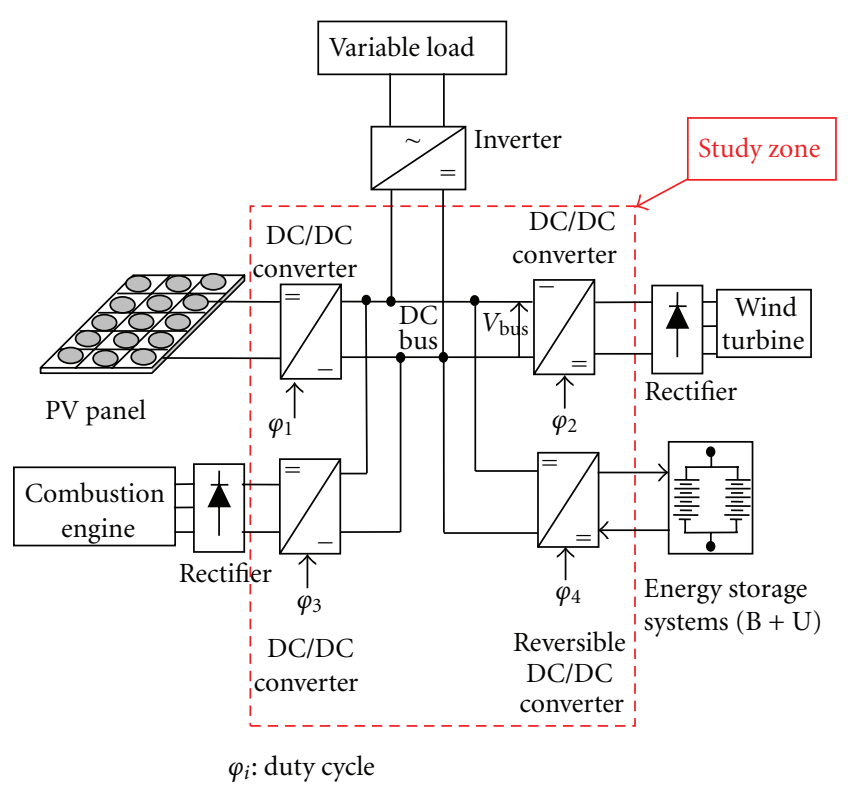

Figure 1: HPS Scheme.

or not, and so forth. Such control level could be achieved by adaptive techniques control such as those employing fuzzy logic.

The paper is organized in five sections. In Section 2, the hybrid power system and their mathematical models are described. Then, in Section 3, I will present the design of low level controller witch performed by a local sliding mode control unit. By applying online dynamic Takagi-Sugeno fuzzy logic principles, the high-level controller design is presented in Section 4. An application to the multisource system is presented in Section 5 in order to illustrate the efficiency of the developed approach. The conclusion sums up the main characteristic of the proposed hierarchical controller and introduces one of the most challenge for adaptive control in the future research.

\section{System Configuration}

The HPS under consideration is shown in Figure 1. It consists of a conventional generation (CE), a renewable energy sources (RES: photovoltaic module and wind turbine), an ESS (batteries and ultracapacitors), and a variable load. All these elements are connected onto a DC bus through DC/DC power electronic converters.

In order to allow ESS charging as well as discharging, the DC/DC converter which connects the ESS to the DC bus is bidirectional unlike what other converters are unidirectional. The DC bus accumulates the generated energy and sends it to the variable load and, if necessary, to the energy storage system. In this configuration, renewable sources take over as main energy source.

\subsection{Models of Energy Sources}

2.1.1. Renewable Sources. The most accessible energy sources are solar and wind energy which can be produced through photovoltaic conversion and wind turbine, respectively. The available photovoltaic (PV) and wind turbine energy production are calculated based on the meteorological information (irradiation, temperature, and wind speed) and their characteristics. In this paper, the photovoltaic and wind turbine power models were obtained, respectively, from $[8$, 9] as follows.

For PV area, the electric model closest to the PV generator is a model with one diode.

The current output of a PV array $\left(\left(N_{p}-N_{s}\right)\right.$ PV cells interconnected in a parallel series) $I_{p}$ can be calculated by

$$
\begin{aligned}
I_{p}= & N_{p}\left[I_{\mathrm{ph}}-I_{s} *\left(\exp \left(\frac{N_{p} V_{p}+N_{s} I_{p} R_{s}}{N_{p} N_{s} V_{T}}\right)-1\right)\right] \\
& -\frac{N_{p} V_{p}+N_{s} I_{p} R_{s}}{N_{s} R_{\mathrm{sh}}}
\end{aligned}
$$

where $V_{T}=\left(n K_{B} T\right) / q$ is the thermodynamic voltage, $V_{p}$ is the voltage level on the PV panel array terminals, $I_{\mathrm{ph}}$ is the photocurrent, and $I_{s}$ the reverse saturation current, $K_{B}$ is the Boltzman constant, and $n$ is the cell deviation from the ideal $p-n$ junction characteristic.

Based on the observation of voltage-power relationship, I can notice that the PV array has a unique voltage point which provides the maximum power [10]. This maximum power point (MPP) can be tracked in real time with a control algorithm called MPPT in order to increase their performances. Several algorithms have been proposed in existing literature [11] such as: perturb and observe, incremental conductance, fractional open circuit voltage, fuzzy control, and neural network. As the objective of this paper is to develop the higher-level control algorithms (energy management strategy), I adopt in the simulation section one of these algorithm (e.g., incremental conductance).

For the wind turbine, the output power of wind generator at wind speed $v$ is expressed as

$$
\begin{gathered}
P_{\mathrm{WT}}(t) \\
= \begin{cases}\frac{\left(v^{3}-v_{\mathrm{ci}}^{3}\right)}{v_{r}^{3}-v_{\mathrm{ci}}^{3}} P_{R} & v_{\mathrm{ci}}<v<v_{r}, \\
P_{R} & v_{r}<v<v_{\mathrm{co}}, \\
0 & v \leq v_{\mathrm{ci}} \text { or } v \geq v_{\mathrm{co}},\end{cases} \\
\quad v(t)=v_{r}(t) \cdot\left(\frac{h}{h_{r}}\right)^{\gamma},
\end{gathered}
$$

where $P_{R}$ is the nominal power; $v, v_{r}, v_{\mathrm{ci}}$, and $v_{\mathrm{co}}$, respectively, are the wind speed at desired height $h$, wind speed at the reference height $h_{r}$, and cut-in and cutoff wind speed of the wind generator.

2.1.2. Combustion Engine. In the case of a renewable energy system, the production of electrical energy is conducted within the resources (wind, sun, ...) and not in demand. For standalone installations, in order to assist the renewable sources in situations of deficient environmental circumstances, it is necessary to resort to storage and/or to add a CE. 
The CE is a conventional power source which is independent from environmental conditions (irradiation, wind velocity, etc.). This source is the site of a complex phenomena and strongly nonlinear. There are several levels, depending on the desired use and degree of complexity of models. In this work, for simplification reasons of system study, I assumed that the dynamic behavior of CE can be approximated by a first-order system with a time constant $\tau[12]$.

2.1.3. Energy Storage Systems. Energy storage is a key factor in a HPS. It can provide energy when needed and store the surplus of production otherwise. Since there is a wide range of storage options, for a given application, both the power and energy rating of the storage device must be considered in the device selection. The most common storage technologies can be summarized in terms of transient and steady-state storage devices. In our case, the energy storage system comprises the batteries and the supercapacitors banks. The combination of these sources makes the best use of the advantages of each individual device and may meet the requirements of the load regarding both power and energy densities.

(1) Batteries. In general, the batteries allow the good storage characteristics for wide ranges of applications such as electric vehicles, hybrid electric vehicles, and electrical networks [13-15]. The mathematical dynamic model of the battery bank used in the simulation program is deducted from the CIEMAT model [16, 17]. Its input is the current battery profile which is positive when power is drawn from the batteries and negative when power is supplied to the batteries. Its output is the state of charge (SOC), which defines the relationship between the battery's total energy and its usable energy (3). We have

$$
\operatorname{SOC}_{\text {min }} \leq \operatorname{SOC}(t)=\operatorname{SOC}(t-1)+\frac{I_{\text {bat }}}{C_{\text {bat }}} \leq \operatorname{SOC}_{\text {max }},
$$

where $I_{\text {bat }}$ is the charge (or discharge) instantaneous current of the battery bank; this current is positive when the batteries are charging and negative otherwise. $C_{\text {bat }}$ is the capacity of battery bank calculated from the average battery current $I b \_m$ as follow:

$$
C_{\text {bat }}=\frac{1.67 * C_{10}}{1+0.67 *\left(I b \_m / I_{10}\right)^{0.9}} *(1+0.005 * \Delta T),
$$

where $\Delta T$ is a battery bank heating relative to the ambient temperature, $C_{10}$ is a nominal capacity of battery bank, and $I_{10}$ is a nominal current of battery bank.

According to the specifications from the manufacturers, in this paper, the battery's lifetime can be prolonged to the maximum if SOC is between 20 and 90\% [17].

(2) Supercapacitors. Supercapacitors are electrical storage devices with a high power density, used for peak power leveling to assist the battery during transients.

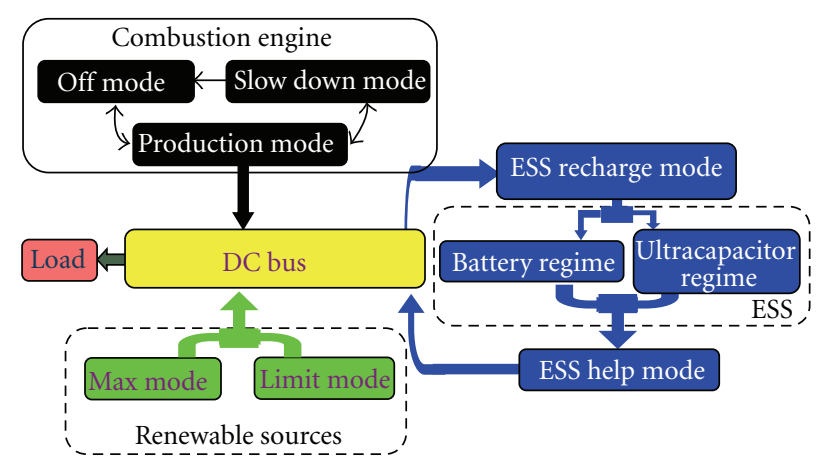

Figure 2: Multisource operating modes.

In contrast to a battery, the voltage of a supercapacitor changes linearly with its state of charge as follows [18]:

$$
\mathrm{SOC}_{\mathrm{UC}}=\frac{4}{3}\left(\frac{C V^{2}}{2 E_{\max }}-\frac{1}{4}\right)
$$

where $C$ is the equivalent total capacity of supercapacitors bank, $V$ is the instantaneous voltage measured at its terminals, and $E_{\max }$ is the maximum stored energy obtained for $V_{\max }$.

In this paper, to ensure good performances and a sufficient lifetime of supercapacitors and to avoid overcharging the maximum voltage was limited to $V_{\max }$, and the discharge rate is fixed at 0.25 .

When all these constraints due to limitations in voltage, current and power are combined, the momentary power output of the supercapacitors can be calculated for every time step.

2.2. Operating Modes of Energy Sources. Because of the variable structure nature of multisource system, the operating modes of each source are summarized in Figure 2.

For renewable sources, there are two possible operating modes: Maxi Mode and Limit Mode. The Maxi Mode occurs when the maximum energy captured from the renewable sources is not enough to satisfy the total power demand (the load plus the ESS recharge requirements). In this case, the MPPT algorithm must be used (i.e., capturing the maximum renewable power $\left(P_{\text {ren_max }}\right)$ available). However, when the provided power is higher than demanded one (Limit Mode), only the required amount of energy is produced.

For CE, there are three possible operating modes: Production Mode (PM), Off Mode (OM), and Slow Down Mode (SDM).

In $\mathrm{PM}$, the $\mathrm{CE}$ assists the renewable sources in order to provide the load power demand and the ESS power recharge.

In OM, the load power demand is provided with renewable sources assisted by ESS, and the CE is off.

In SDM, the load power demand is only provided with renewable sources, and the CE is relaxed to avoid transient phase and overheating. This is important to avoid running the CE for very short period of time. 


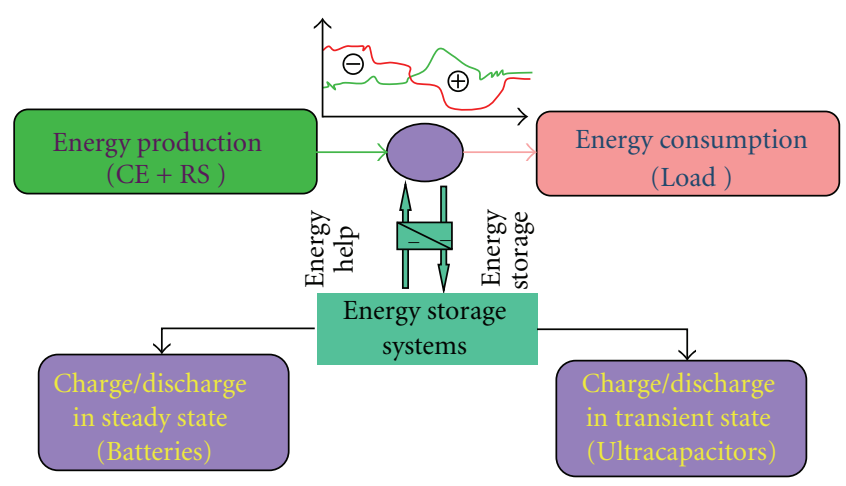

FIGURE 3: Energy storage management strategy.

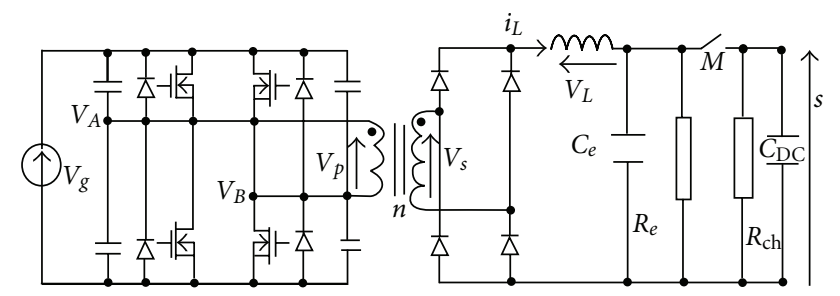

FIGURE 4: Structural diagram of the ZVS full bridge isolated DC/DC converter.

For ESS, depending on the flow of power, there are two possible operating modes, Help Mode (HM) and Recharge Mode (RM).

In the HM, the power demand is provided by the renewable sources assisted by ESS while the CE is switched off and renewable sources power is lower then demanded one.

In the RM, when the load energy demand is smaller than a produced power, the redundant energy is used to charge the ESS.

According to profile of the redundant energy (Figure 3), I can distinguish two charge/discharge cycles: steady-state cycle ensured by batteries and transient-state cycle ensured by ultracapacitors, which are used for peak power leveling to assist the batteries during hard power demand.

In order to improve system operation, the power and energy management strategy has to decide which operating mode must be used.

\section{Low-Level Controller}

The DC/DC converters are basic constituents of the multisource system. The aim of these converters is to regulate the DC component of the output voltage to its reference by controlling the current provided by each source in spite of the voltage variations on their inputs.

\subsection{Multimodel of Several DC/DC Power Converters Coupled} on a DC Bus. An accurate model for the coupling of DC/DC power converters on a DC bus has been developed previously in [19].

The ZVS full-bridge isolated DC/DC converter [20, 21], studied in this paper, is represented on Figure 4.

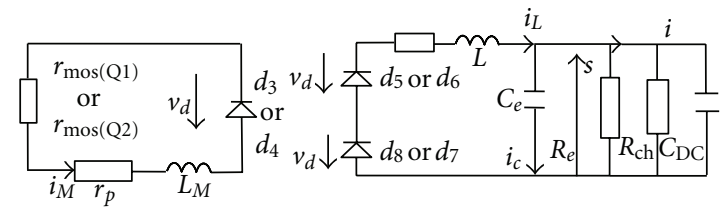

FIgURe 5: Phases 1 and 3.

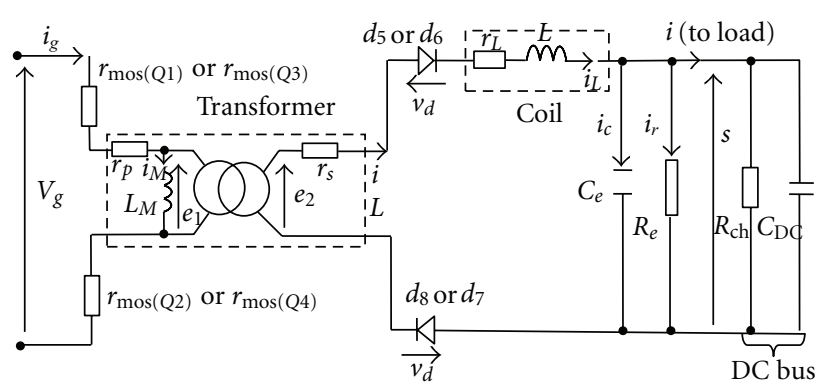

Figure 6: Phases 2 and 4.

It supposed that it runs in a continuous conduction mode.

Four basic structures of operation may be distinguished.

Phase 1: (Q1Q4) On and (Q2Q3) Off.

Phase 2: (Q1d3) On.

Phase 3: (Q2Q3) On and (Q1Q4) Off.

Phase 4: (Q2d4) On.

The structural diagram corresponding to the operation phases 1 and 3 is depicted in Figure 5 and the one corresponding to the operation phases 2 and 4 is represented on Figure 6. $r_{p}$ and $r_{s}$ are, respectively, the transformer primary and secondary resistances. $L_{M}$ is the transformer magnetizing inductance. $C_{\mathrm{DC}}$ is the DC bus capacity, and the load $R_{\mathrm{ch}}$ is supposed resistive.

The voltage source $\left(V_{g}\right)$ is disconnected during phases 2 and 4 which correspond to the transformer demagnetization (Figure 4), so $i_{g}=0$.

Each phase leads to the following state space model:

$$
\dot{x}=A_{i} x+B_{i} u,
$$

where $x=\left[\begin{array}{lll}i_{M} & i_{L} & V_{\text {bus }}\end{array}\right]^{T}$ is the state vector, and $u=$ $\left[\begin{array}{ll}V_{g} & V_{d}\end{array}\right]^{T}$ is the control vector.

$i_{M}, i_{L}, V_{\text {bus }}, v_{g}$, and $v_{d}$, respectively, represent the transformer magnetizing current, the inductance current, the DC/DC power converters output voltage, the source, and the diode voltage. It is assumed that diodes are not ideal. We have 


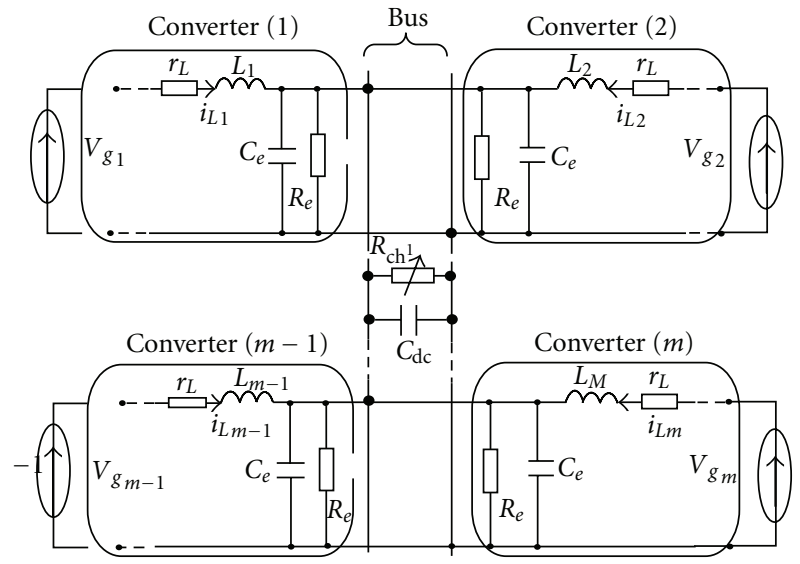

FIgURE 7: Structural diagram of the coupling of $m$ DC/DC power converters.

$$
\begin{aligned}
& A_{1}= \\
& {\left[\begin{array}{ccc}
\frac{-\left(2 R_{\mathrm{mos}}+r_{p}\right)}{L_{M}} & \frac{-n\left(2 R_{\mathrm{mos}}+r_{p}\right)}{L_{M}} & 0 \\
\frac{-n\left(2 R_{\mathrm{mos}}+r_{p}\right)}{L} & \frac{-n^{2}\left(2 R_{\mathrm{mos}}+r_{p}\right)-\left(r_{s}+r_{L}\right)}{L_{1}} & \frac{-1}{L} \\
0 & \frac{1}{C_{\mathrm{eq}}} & -\frac{1}{R_{\mathrm{eq}} C_{\mathrm{eq}}}
\end{array}\right],}
\end{aligned}
$$

$$
A_{3}=
$$$$
\left[\begin{array}{ccc}
\frac{-\left(2 R_{\mathrm{mos}}+r_{p}\right)}{L_{M}} & \frac{+n\left(2 R_{\mathrm{mos}}+r_{p}\right)}{L_{M}} & 0 \\
\frac{-n\left(2 R_{\mathrm{mos}}+r_{p}\right)}{L} & \frac{-n^{2}\left(2 R_{\mathrm{mos}}+r_{p}\right)-\left(r_{s}+r_{L}\right)}{L} & \frac{-1}{L} \\
0 & \frac{1}{C_{\mathrm{eq}}} & -\frac{1}{R_{\mathrm{eq}} C_{\mathrm{eq}}}
\end{array}\right]
$$

$$
\begin{gathered}
A_{2 / 4}=\left[\begin{array}{ccc}
\frac{-\left(R_{\mathrm{mos}}+r_{p}\right)}{L_{M}} & 0 & 0 \\
0 & \frac{-r_{L}}{L} & \frac{-1}{L_{1}} \\
0 & \frac{1}{C_{\mathrm{eq}}} & -\frac{1}{R_{\mathrm{eq}} C_{\mathrm{eq}}}
\end{array}\right] \\
B_{1}=\left[\begin{array}{ccc}
\frac{1}{L_{M}} & \frac{n}{L} & 0 \\
0 & \frac{-2}{L} & 0
\end{array}\right]^{T} \\
B_{3}=\left[\begin{array}{ccc}
\frac{n}{L_{M}} & \frac{n}{L} & 0 \\
0 & \frac{-2}{L} & 0
\end{array}\right]^{T} \\
B_{2 / 4}=\left[\begin{array}{ccc}
0 & 0 & 0 \\
0 & 0 & 0
\end{array}\right]^{T} .
\end{gathered}
$$

Combining the above phase states model, the average model of the DC/DC converter shown in Figure 4 can be derived as follows $[22,23]$ :

$$
\dot{x}(t)=f(x, u)+g(x, u) \varphi(t)
$$

where

$$
\begin{gathered}
f(x, u)=a x(t)+b u(t), \\
g(x, u)=A x(t)+B u(t), \\
A=\frac{1}{2}\left(A_{1}-A_{2}+A_{3}-A_{4}\right), \\
a=\frac{1}{2}\left(A_{2}+A_{4}\right), \\
B=\frac{1}{2}\left(B_{1}-B_{2}+B_{3}-B_{4}\right), \\
b=\frac{1}{2}\left(B_{2}+B_{4}\right) .
\end{gathered}
$$

The average model of the DC/DC converter developed above can be extended to the coupling of many renewable sources [24]. I suppose that the DC/DC power converters are identical.

The partial structural diagram of the coupling of $m$ DC/DC power converters is represented in Figure 7.

The multimodel for $m$ DC/DC converters coupled on a DC bus is express as follows:

$$
\dot{X}(t)=F(X, u)+G(X, u) \varphi(t),
$$

where

$$
\begin{gathered}
F(X, U)=\left[f_{1}\left(x_{1}, u_{1}\right), \ldots, f_{m}\left(x_{m}, u_{m}\right)\right]^{T}, \\
G(X, U)=\operatorname{diag}\left[g_{1}\left(x_{1}, u_{1}\right), \ldots, g_{m}\left(x_{m}, u_{m}\right)\right], \\
X=\left[x_{1}, \ldots, x_{m}\right]^{T}, \\
U=\left[u_{1}, \ldots, u_{m}\right]^{T}, \\
\varphi=\left[\varphi_{1}, \ldots, \varphi_{m}\right]^{T} .
\end{gathered}
$$

The multimodel parameters ( $F$ and $G$ ) change according to the DC/DC power converters coupled on the DC bus.

For simplicity of presentation, in this subsection, only two coupling sources are considered $(m=2)$.

3.2. Dynamic Controller Design for DC/DC Converter. The variable structure systems (VSS) theory [25] can be extremely helpful in the study of the control of powers DC/DC converters. The switched mode DC/DC converters are nonlinear, and it is not suitable to the application of linear control theory.

A different approach, which complies with the nonlinear nature of switch-mode power supplies, is proposed. In this context, the sliding mode control, which is derived from the VSS theory, appears as a powerful control technique that offers several advantages: stability even for large supply 


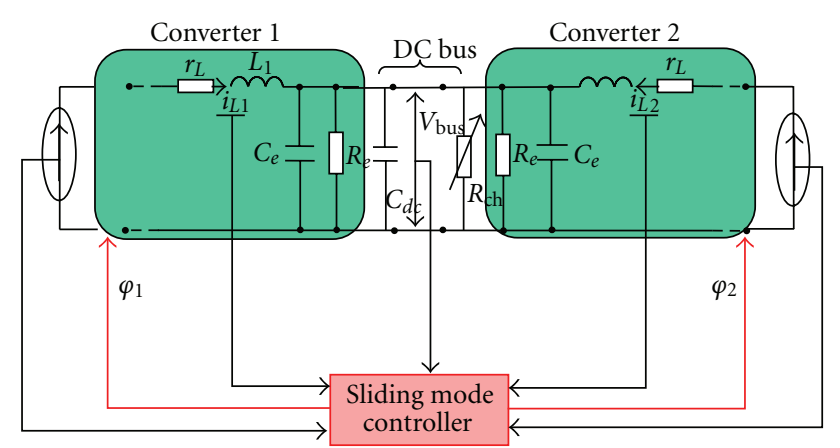

FIGURE 8: MIMO sliding mode robust control scheme.

and load variations, robustness, good dynamic response and simple implementation. Their capabilities emerge especially in application to high-order converters, yielding improved performances as compared to usual control techniques.

In this subsection, I design a sliding mode dynamic controller "SMDC" which regulates the voltage level on the DC bus by controlling the current provided by each source.

In various works in the literature, a cascade control structure with two control loops for DC/DC converters control is usually adopted [26, 27]. In this structure, an inner current loop regulates the inductor current, whereas an external control loop keeps a constant output voltage.

However, this structure has some drawbacks such as the value of reference current that may be poorly estimated because of quick variations of the load and the sources. The current estimation error introduces a bus voltage error compared to the reference one. This affects the controller performances in terms of robustness.

To overcome this issue, I adopt, in this paper, a MIMO sliding mode robust control scheme (Figure 8).

The development of the sliding mode control scheme consists of two phases. The first is to design a sliding surface where the DC/DC converter exhibits desired properties. The second is to design a control law to drive and maintain the system on the sliding surface $[26,27]$.

In order to act simultaneously on all state variables, let us define the following PI-type sliding surface:

$$
\delta_{i}(t)=e_{i}(t)+\alpha \int_{0}^{t} e_{i}(\tau) d \tau, \quad i=1,2,
$$

where

$$
e_{i}(t)=k_{i}\left(I_{\mathrm{Li}}-I_{\text {Li_ref }}\right)+k_{3}\left(V_{\text {bus }}-V_{\text {bus_ref }}\right) .
$$

$I_{\text {Li_ref }}, V_{\text {bus_ref }}$ are the references of inductor current and voltage DC bus. $k_{1,2,3}$ are the tracking weight factor error, and $\alpha>0$ is the sliding-surface integral parameter.

In the following, a bounded control input is designed to force $\delta_{i}(t)$ to converge to zero or make its absolute value smaller.

We obtain the equivalent control $\varphi_{\mathrm{eq} 1,2}$ by applying the invariance condition:

$$
\delta_{i}(t)=\dot{\delta}_{i}(t)=0, \quad \text { with } \varphi_{i}(t)=\varphi_{\text {eqi }}(t), \quad i=1,2 .
$$

From (17), the time derivative of $\delta_{i}(t)$ along system (15) is given as

$$
\begin{aligned}
\dot{\delta}_{i}= & k_{i}\left(A_{2-} x_{i}+B_{2-} u_{i}\right) \varphi_{\text {eqi }}+k_{i}\left(a_{2-} x_{i}+b_{2-} u_{i}-\dot{I}_{\text {Li_ref }}\right) \\
& -k_{3}\left(A_{3-} x_{i}+B_{3-} u_{i}-\dot{V}_{\text {bus_ref }}\right)+\alpha e_{i}=0 .
\end{aligned}
$$

The notation $A_{2-}$ refers to the second column of the $A$ matrix.

Thus, the equivalent control input is given as

$$
\varphi_{\mathrm{eqi}}=-\frac{R_{i}}{H_{i}}, \quad i=1,2,
$$

where

$$
\begin{aligned}
R_{i}= & k_{i}\left(a_{2-} x_{i}+b_{2-} u_{i}-\dot{I}_{\text {Li_ref }}\right) \\
- & k_{3}\left(A_{3-} x_{i}+B_{3-} u_{i}-\dot{S}_{\text {ref }}\right)+\alpha e_{i}, \\
& H_{i}=k_{i}\left(A_{2-} x_{i}+B_{2-} u_{i}\right) .
\end{aligned}
$$

It is well known that the exact value of the external disturbance and the parameter variations of the system, such as internal resistance and magnetizing current, are difficult to measure in advance for practical applications. Therefore, I propose a nonlinear switching control-input $\varphi_{\text {si }}$ to estimate the upper bound of uncertainties and external disturbance:

$$
\varphi_{\mathrm{si}}(t)=-\frac{\gamma_{i}(t)}{H_{i}(t)} \operatorname{sign}\left(\delta_{i}(t)\right) .
$$

In the presence of parameter uncertainties and external disturbances the dynamic equation (15) becomes

$$
\dot{X}(t)=F(x)+G(x) \varphi+\Delta(t),
$$

where $\Delta$ includes the uncertainties and perturbations.

In order to reduce chattering, the most common method is to replace the sign function by the saturation function $\operatorname{sat}(\delta(t), \zeta)$, where

$$
\operatorname{sat}(\delta(t), \zeta)= \begin{cases}\operatorname{sign}(\delta), & |\delta|>\zeta>0, \\ \frac{\delta}{\zeta}, & |\delta| \leq \zeta\end{cases}
$$

and $\zeta$ is a small positive constant.

Hence, the SMDC rule can be designed as

$$
\varphi_{i}(t)=\varphi_{\mathrm{eqi}}(t)-\frac{\gamma_{i}(t)}{H_{i}(t)} \operatorname{sat}\left(\delta_{i}(t), \zeta\right)
$$

The main theorem, stated and proved below, provides sufficient conditions to ensure the stability and robustness of the multisources system.

Theorem 1. Let the nonlinear multisources system given by (15) and sliding surface given by (17), and suppose that the Lyapunov function is defined by

$$
V(t)=\frac{1}{2} \delta_{1}(t)^{2}+\frac{1}{2} \delta_{2}(t)^{2} .
$$


TABLE 1: NMSE.

\begin{tabular}{ll}
\hline PI & SMDC \\
\hline 1.2483 & 0.0075 \\
\hline
\end{tabular}

Then, the sufficient stability condition for the SMDC in the sense of Lyapunov should satisfy the following range of switching gains:

$$
\gamma_{i}(t) \geq|\Delta(t)|, \quad i=1,2,
$$

where $|\Delta|$ represent the upper bound of the uncertainties and perturbations.

Proof. If $V(t)$ is a Lyapunov function candidate defined as in (28), the asymptotic stability will be satisfied if $\dot{V}(t) \leq 0$, with

$$
\dot{V}(t)=\delta_{1}(t) \dot{\delta}_{1}(t)+\delta_{2}(t) \dot{\delta}_{2}(t)
$$

Using (17), (25), and (27) in (30) I obtain

$$
\begin{aligned}
\dot{V}(t)= & \delta_{1}(t)\left[-\gamma_{1}(t) \operatorname{sat}\left(\delta_{1}(t), \zeta\right)+\Delta(t)\right] \\
& +\delta_{2}(t)\left[-\gamma_{2}(t) \operatorname{sat}\left(\delta_{2}(t), \zeta\right)+\Delta(t)\right] \leq 0 .
\end{aligned}
$$

As a conclusion, to satisfy the condition $\dot{V}(t) \leq 0$, and to compensate the bounded parametric uncertainties and disturbances, I must restrict to sufficient condition (29).

3.3. Evaluation of Low Level Control Design. To illustrate the low level control design and performance evaluation of my structure, a hybrid power system coupled to two sources through a similar DC/DC converter is considered. The characteristics of the full bridge converters are

$$
\begin{gathered}
R_{\mathrm{mos}}=0.005 \Omega, \quad R_{l}=2 \Omega, \quad n=12, \\
V_{d}=0.3 \mathrm{v}, \quad L=1 e-3 \mathrm{H}, \\
L_{m}=20 e-6 \mathrm{H}, \quad r_{p}=0.05 \Omega, \\
r_{s}=0.05 \Omega, \quad C_{e}=20 e-6 \mathrm{~F}, \\
R_{e}=56 e 3 \Omega, \quad C_{\mathrm{DC}}=10 e-6 \mathrm{~F} .
\end{gathered}
$$

The DC bus voltage reference is set at $100 \mathrm{~V}$. Simulations are obtained with sampling interval $\mathrm{Te}=50 \mu \mathrm{s}$.

We suppose that $40 \%$ of the load demands are supplied with the first source and $60 \%$ with the second one.

Responses obtained with my algorithm are compared with ones resulting from the PI algorithm with cascade structure. The linearization techniques are applied to the converters in order to deduce linear parameters [28]. trollers.

The simulation conditions are identical for both con-

To compare the global performances of my algorithm with PI one, let us consider the normalised mean square error
(NMSE, Table 1), that is interpreted as the overall deviations between output plant and desired values and is defined as:

$$
\mathrm{NMSE}=\frac{\sum_{l}\left(V_{\text {bus }}-V_{\text {bus_ref }}\right)^{2}}{\sum_{l}\left(V_{\text {bus_ref }}\right)^{2}} .
$$

In order to test the capacity of SMDC to reject disturbances, and to investigate the robustness of the control scheme, the load and sources dynamics of the hybrid system are supposed fast. The sources and load profiles are represented by Figures 9 and 10 .

The closed-loop responses of load current DC bus voltage, tracking voltage error, and load current obtaining with PI controller and sliding mode controller are shown in Figures 11, 12, and 13, respectively.

Given the fast dynamics imposed on the sources and the load as evident from Figures 9 and 10, the simulation results reveal that the SMDC is advantageous in providing negligible steady-state errors $(\mathrm{NMSE}=0.0075)$, to adjust the flow source that meets the load demand and guaranteed stable system (Figure 12). It can also be seen that the responses are satisfactory in terms of overshoot, settling time, and fall time. This shows an excellent behavior of the sliding mode controller in comparison with PI controllers which does not run correctly for wide variations of operating point.

\section{High Level Controller: Intelligent Power and Energy Management Strategy}

Generally, an HPS is a dynamic system of electric power production. While during their operation, fluctuation in wind speed, solar radiation, and load demand will occur, to ensure a reliable power supply under all operating conditions, the global control strategy is critical to control efficiently the energy flow in the multisource system.

Indeed, under the operation constraints related to each type of sources, the energy flow must be managed such that the load demand is satisfied for all time (preserve the reliability of the system), the ESS is managed in an optimal way (the battery and ultracapacitor SOC minimum and maximum threshold values which must be respected, and the current and voltage should be limited to maximum absolute value in order to increase the ESS durability), and the fuel use is optimal.

These requirements are achieved by improving the rate of renewable energy penetration, by an appropriate controller of $\mathrm{CE}$ and finally, and by a specific management of the charge-discharge ESS operation.

Since the desired behavior of the multisource system is well known and can be described using linguistic variables, the use of an online Takagi-Sugeno fuzzy dynamic supervisor seems appropriate. Indeed, the fuzzy approach has many advantages, such as the possibility to use multiple input variables without increasing the complexity of the controller, and the desired behavior can be described by simplifies linguistic variables but it would be difficult to express mathematically and finally, historical data is stored only for a short time window, which perfectly meets the real-time application requirements. 


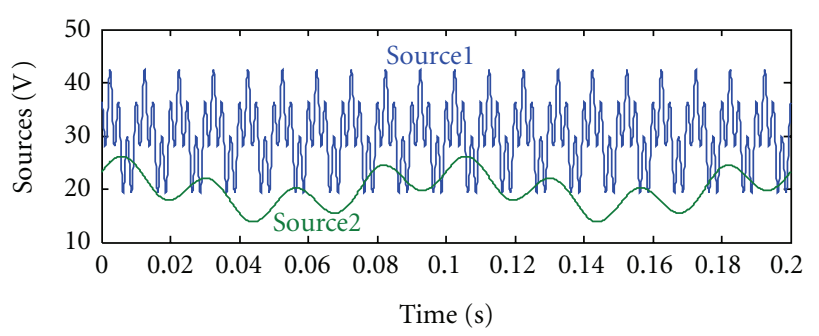

FIgURE 9: Sources profiles.

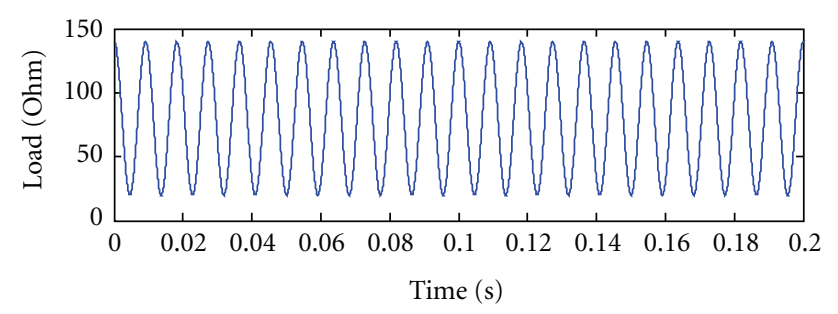

Figure 10: Load profiles.

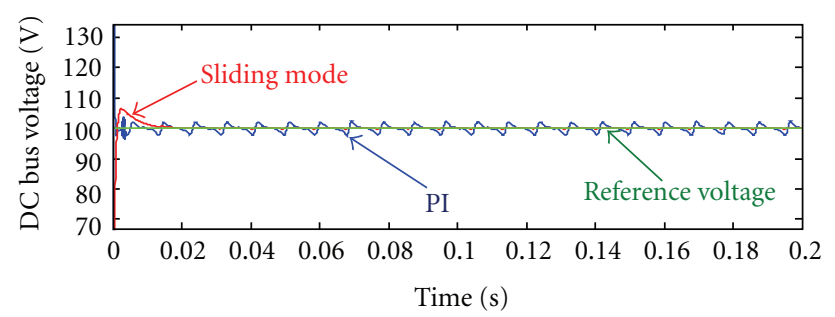

FIGURE 11: DC bus voltage plot obtained with PI controller and sliding mode controller.

4.1. FLC's Structure. Based on reviews of multisource power, the block diagram of the global control strategy is illustrated in Figure 14.

The required behavior was implemented with the help of six input variables (the energy sources availability and load power demand). These information are useful to determine whether there is surplus or deficient energy to supply the load demand.

The load power estimation (P_load) and there variation $(\triangle P$ load) are used to evaluate instantaneously the load requirements and to decide which ESS operating mode must be used (battery with high-specific energy or ultracapacitor with high-specific power).

The SOCs of ESS are used to prevent an excessive discharge or an overcharge of the ESS and to know how much supply energy is available. It is estimated from the SOC model calculated depending on ESS power (batteries and ultracapacitors) that is also a fuzzy output.

The online dynamic fuzzy logic controller output variables are a reference power vector (power set points: battery power $\left(P_{\text {bat }}\right)$, ultracapicitor power $\left(P_{\mathrm{uc}}\right)$, combustion engine produced power and $P_{\text {ren }}$ ) sent to the low level control, and $\mathrm{CE}$ required power sent to the $\mathrm{CE}$ controller.

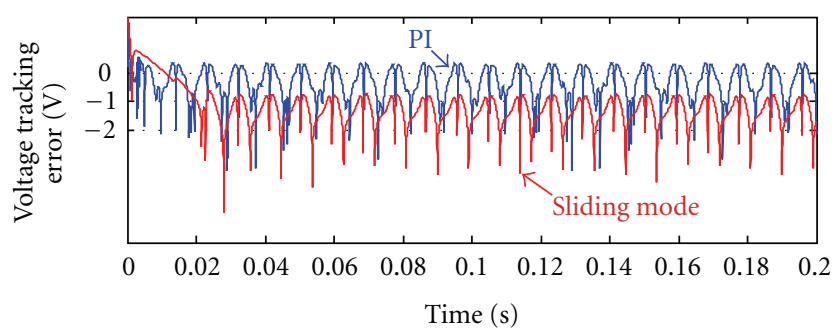

FIGURE 12: Tracking voltage error plot (logarithmic scale) obtained with PI controller and sliding mode controller.

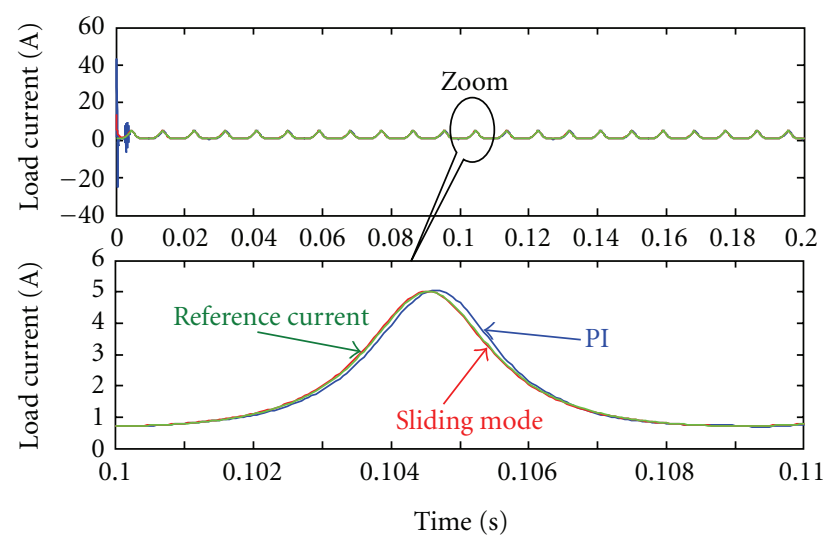

Figure 13: Load current plot obtained with PI controller and sliding mode controller.

4.2. Membership Functions. Trapezoidal type membership functions were used for the linguistic input variables, as shown in Figures 15(a) to 15(e), because they produce smoother control action due to the flatness at the top of the trapezoidal shape [5].

The battery state of charge $\left(\mathrm{SOC}_{\mathrm{bat}}\right)$ input was divided using the linguistic variables: too low (TL), low (L), normal $(\mathrm{N})$ and high $(\mathrm{H})$, as shown on Figure 15(a). The SOC window defines the relationship between the battery's total energy and its usable energy. Fuzzy sets (TL) and $(\mathrm{H})$ represent the ranges where the SOC should not be. Fuzzy set $(\mathrm{N})$ represents the range where the SOC should be, and (L) acts as an energy reserves level necessary to satisfy the load power requirement, when the $\mathrm{CE}$ is on start-up phase.

The membership function for ultracapacitor state of charge $\left(\mathrm{SOC}_{\mathrm{uc}}\right)$ is presented at Figure 15(b). Fuzzy sets (L) and $(\mathrm{H})$ represent the ranges of ultracapacitor operating limit value. Fuzzy set $(\mathrm{N})$ represents the optimal SOC range.

Depending on the instantaneous load power demand, the membership function for renewable power $\left(P_{\text {ren }}\right)$ is divided of two ranges: positive $(+)$ and negative $(-)$ (Figure 15(c)).

The fuzzy set (-) represents the range where the renewable sources must be assisted by ESS or CE to satisfy the power demand. Fuzzy set $(+)$ represents the autonomous supply mode ensured by renewable sources (ESS is on recharge mode and CE is on Off mode).

The demand power variation was divided using the variables positive $(+)$ and negative $(-)$, as shown in Figure 15(d). This information is useful to prevent abusive use of the 


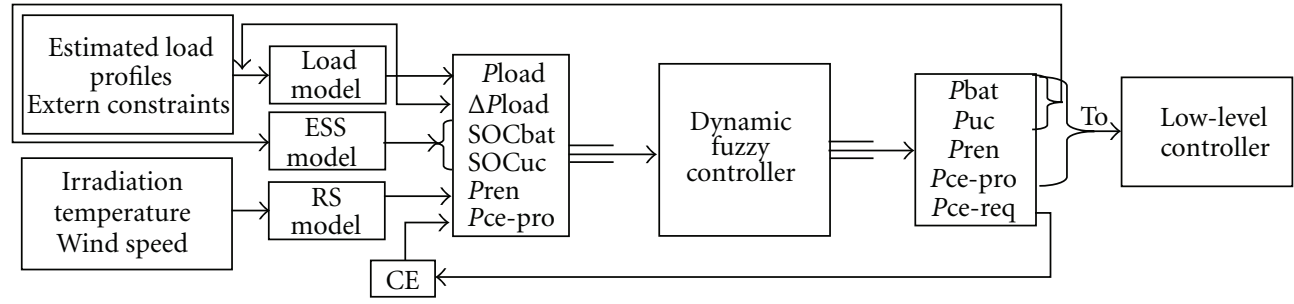

FiguRe 14: Block diagram of dynamic fuzzy logic controller for power management strategy.

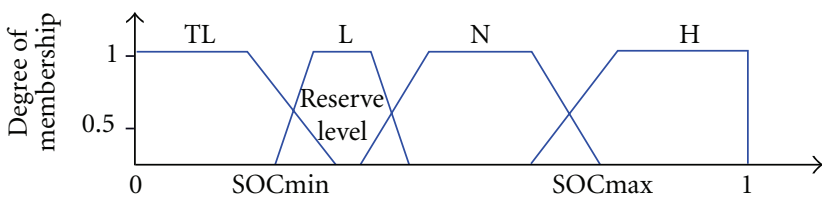

(a)

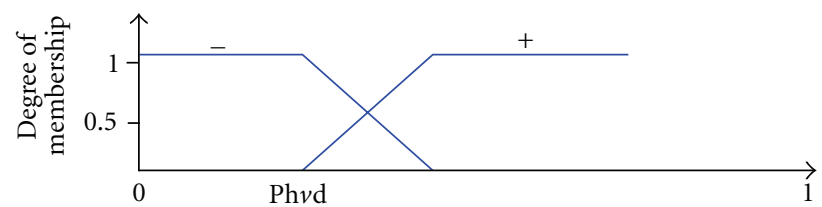

(c)

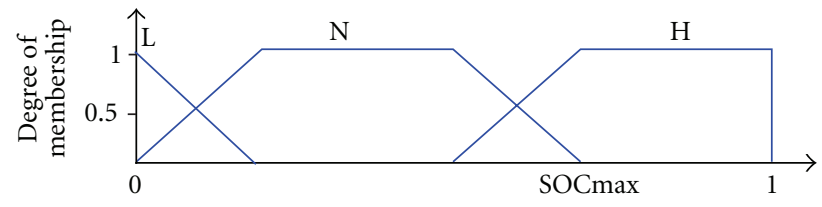

(b)

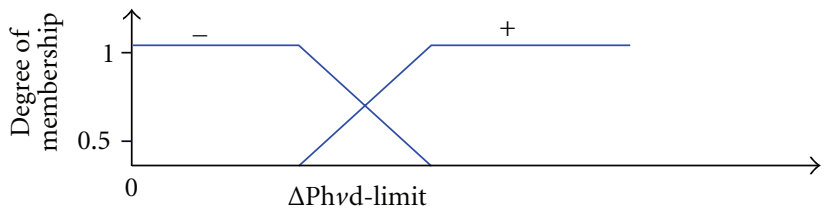

(d)

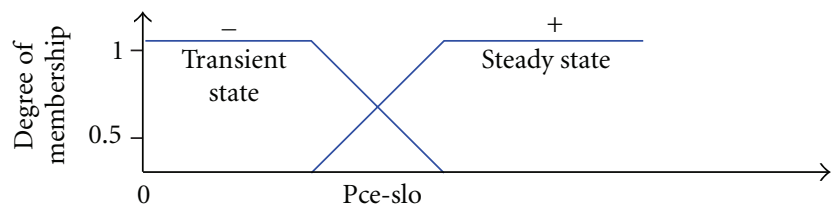

(e)

FIGURE 15: Input membership functions for: (a) SOCbat, (b) SOCuc, (c) renewable energy power, (d) load demand power variation, and (e) $\mathrm{CE}$ power (Pce-slo: combustion engine slow down power).

batteries. In fact, when the demand power variation is below a predetermined level, the ESS discharge-mode must be ensured by batteries; otherwise, the ESS discharge mode must be ensured by ultracapacitor (absorption the peaking power demand).

The membership function for CE power is presented at the Figure 15(e). The fuzzy sets $(+)$ represent the CE Production mode (the power from the generator is effective to supply the load and, simultaneously, recharge the ESS if necessary). The fuzzy sets (-) represent the CE slow-down mode or transient state (the generator do not contribute to provide load power).

4.3. Rules. The rules were chosen very intuitively according to the main following points.

(1) A RES takes over as main energy source.

(2) In the optimal conditions, the battery bank and the ultracapacitor have been dimensioned in order to satisfy the maximum load power demand; that is, $100 \%$ of the energy demand can be supplied by the ESS.
(3) An ESS comes into play in order to balance the renewable power fluctuations and to allow for a $\mathrm{CE}$ Off mode (zero emission).

(4) The CE is turned on when the ESS state of charge drops below a minimum value and renewable power is insufficient to meet the load.

(5) The minimum period of CE operation must cover the ESS time of recharge.

The latter (4 and 5) are important to avoid running the CE for very short period of time.

Using these linguistic directives, it makes easy to obtain a set of fuzzy rules. Thus, the fuzzy rule basis consists of a collection of fuzzy if-then rules type. For example, one of the energy management rules (rule1) can be stated as (IF the renewable power exceeds load demand power AND battery state of charge is high AND ultracapacitor state of charge is high THEN the renewable produced power is equal to load demand power). Using these linguistic variables, a set of fuzzy rules was developed. For the sake of simplicity, the rules number was minimized to 16 rules. These rules are shown in (Table 2). Where $P_{\text {bat_max }}$ is a maximum battery power, $P_{\text {uc_max }}$ is a maximum ultracapacitor power, 

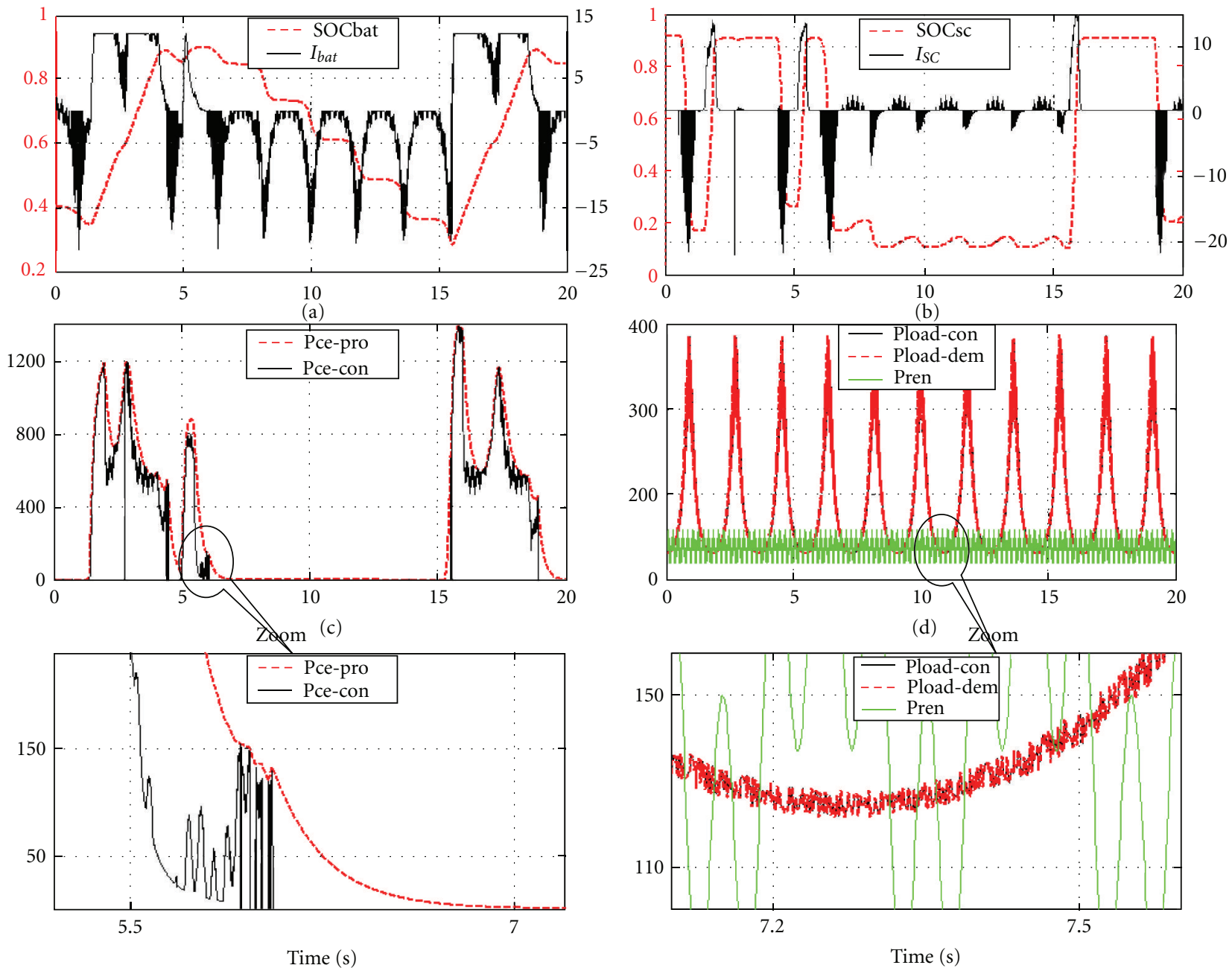

(e)

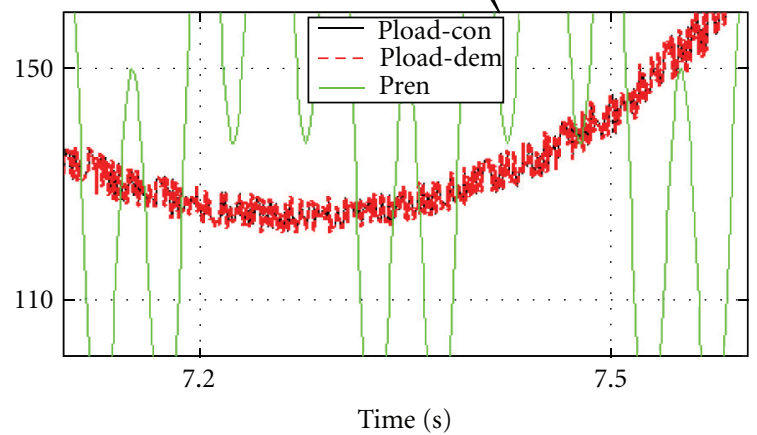

(f)

Figure 16: Simulation results for the power balance of the HES: (a) and (b) present the SOC and currant (A), respectively, of battery and ultracapacitor, (c) shows the generated and consumed power (W) output from the combustion engine, and (d) shows the generated power (W) output from the renewable sources, the demanded and consumed power by the load.

$P_{\text {bat_rech }}$ is a recharge battery power, and $P_{\text {uc_rech }}$ is a recharge ultracapicitor power.

The logical AND (resp.) has been implemented with the minimum (resp. maximum) operator.

While the fuzzy input variables are obtained either from a prediction method based on the model of each source or else using local measurements, to obtain the output of the controller, the degrees of membership functions of the ifparts of all rules are evaluated, and the THEN-parts of all rules are averaged, weighted by these degrees of membership functions.

\section{Application to the Multisource System}

The objective of this simulation is not to produce a realistic practical scenario of HES, but to validate the developed energy management strategy. For this reason, the simulations are made with simplified models of renewable sources, CE, battery and ultracapacitor. Furthermore, the simulations aim to show that the developed energy management strategy can operate in different system configurations with different characteristics. Therefore, any HES state can be controlled without redesign the energy management strategy.

In the presented simulations, to illustrate all possible operating modes of multisource system, I suppose that the battery time constant is reduced to few seconds $(5 \mathrm{~s})$. The simulation results for the power balance of the HES are presented in Figure 16.

It can be observed from these results that the optimal operation objective of HES as mentioned below has been achieved.

(1) The renewable sources take over as main energy sources.

(2) An energy storage system comes into play in order to balance the renewable power fluctuations and to allow for a CE Off mode (zero emission). 


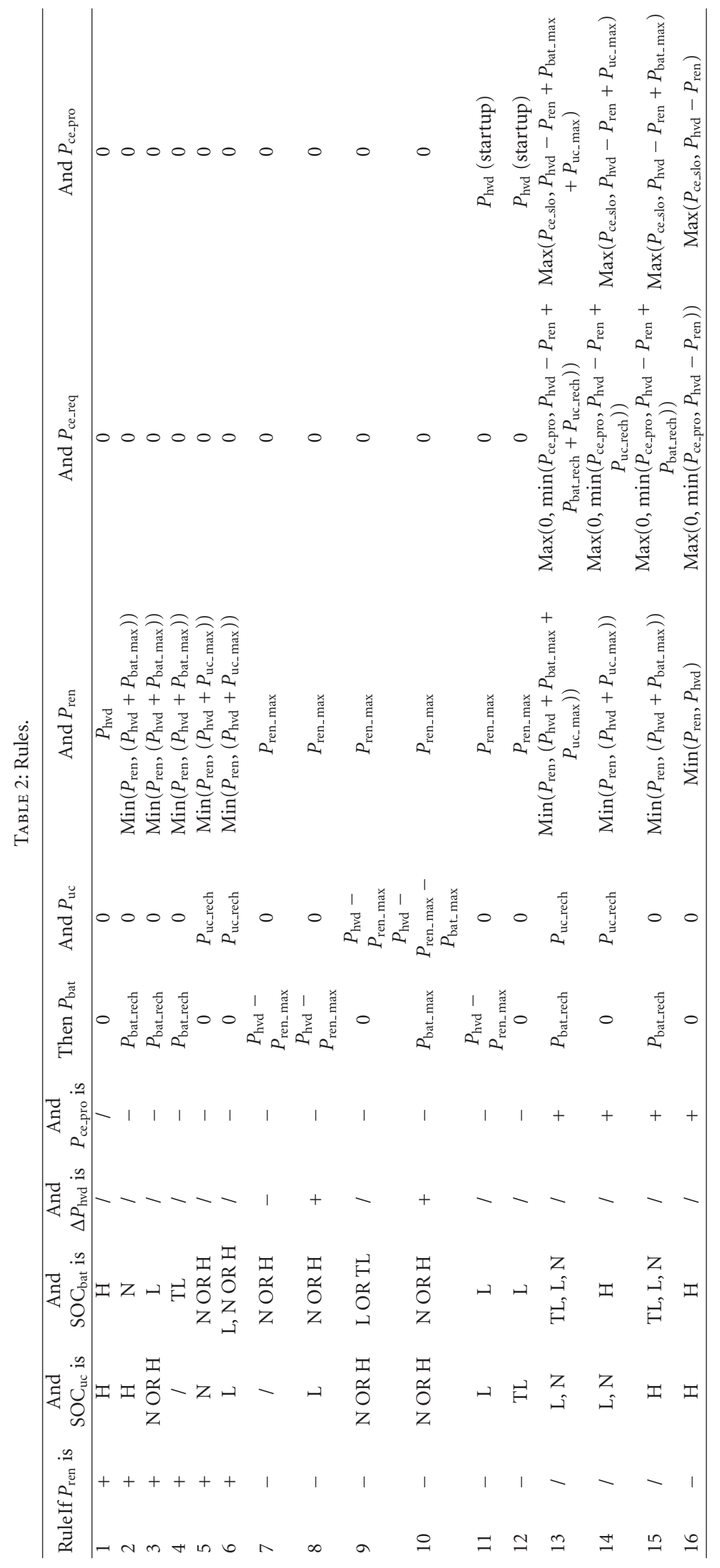


(3) The battery and ultracapacitor SOCs were stable basically and decreased (current is negative)/increased (current is positive) slightly from 0.3 to 0.9 (the operation limits).

(4) The CE turns on when the ESS state of charge drops below a minimum value, and renewable power is insufficient to meet the load (as shown in Figure 16(c) at $2 \mathrm{~s}$ and $17 \mathrm{~s})$.

(5) The minimum period of CE operation covers the ESS time of recharge (as shown in Figure 16(c) between $2 s-7 s$ and $17 s-20 s)$.

(6) Load demand is satisfied for all time which preserve the reliability of the system (Figure 16(d)).

\section{Conclusion and Prospects}

This paper presented the basis for the development of an intelligent and autonomous energy management strategy for HPS. Two hierarchical levels are presented to control and manage the HPS. The low level is performed by a local sliding mode control unit (DC-DC converters controller) of the different power sources. This control technique provides good overall performances compared to standard current control and good robustness against load and input voltage variations. The high level is performed by the online supervisor unit. This unit is designed by applying online dynamic Takagi-Sugeno fuzzy logic principles. As a result the robust control system gets rid of the limits of the HPS, which has the imprecision, uncertainty, strong coupling, and nonlinearity.

Under the operation constraints related to each type of sources, it can be observed from the simulation results that the optimal operation objective of HES has been achieved (the load demands are satisfied for all time, the energy storage system is managed in an optimal way, and the fuel use is optimal).

The application of the proposed control scheme to large-scale renewable multi-source power systems will be considered in my future work.

The neural-based adaptive observer, in order to identify unknown functions in the multi-source system and to estimate the unmeasured states, will be also studied in my further works.

\section{References}

[1] Y. Chen and W. Jie, "Agent-based energy management and control of a grid-connected wind/solar hybrid power system," in Proceedings of the 11th International Conference on Electrical Machines and Systems (ICEMS '08), pp. 2362-2365, October 2008.

[2] E. Ortjohann, O. Omari, M. Lingemann et al., "An online control strategy for a modular DC coupled hybrid power system," in Proceedings of the European Conference on Power Electronics and Applications (EPE'07), September 2007.

[3] D. Lu, T. Zhou, H. Fakham, and B. Francois, "Design of a power management system for an active PV station including various storage technologies," in Proceedings of the 13th
International Power Electronics and Motion Control Conference (EPE-PEMC '08), Poznan, Poland, September 2008.

[4] M. E. Torres-Hernández and M. Vélez-Reyes, "Hierarchical control of Hybrid Power Systems," in Proceedings of the 11th IEEE International Conference on Power Electronics Congress (CIEP '08), pp. 169-176, August 2008.

[5] A. Bilodeau and K. Agbossou, "Control analysis of renewable energy system with hydrogen storage for residential applications," Journal of Power Sources, vol. 162, no. 2, pp. 757-764, 2006.

[6] S. Kermani, S. Delprat, R. Trigui, and T. M. Guerra, "Predictive energy management of hybrid vehicle," in Proceedings of the IEEE Vehicle Power and Propulsion Conference (VPPC '08), September 2008.

[7] M. Mohebbi, M. Charkhgard, and M. Farrokhi, "Optimal neuro-fuzzy control of parallel hybrid electric vehicles," in Proceedings of the IEEE Vehicle Power and Propulsion Conference (VPPC '05), pp. 252-256, September 2005.

[8] F. Soltani and N. Debbache, "Integration of converter losses in the modelling of hybrid photovoltaic-wind generating system," European Journal of Scientific Research, vol. 21, no. 4, pp. 707-718, 2008.

[9] R. Belfkira, R. Reghem, J. Raharijaona, G. Barakat, and C. Nichita, "Non linear optimization based design methodology of wind/PV hybrid stand alone system," in Proceedings of the European Association for Vision and Eye Research (EVER '09), Monaco, France, March 2009.

[10] X. Lu and S. H. Yang, "Solar energy harvesting for ZigBee electronics," in International Conference on Sustainability in Energy and Buildings, pp. 19-27, Brighton, UK, 2009.

[11] B. Ai, H. Yang, H. Shen, and X. Liao, "Computer-aided design of PV/wind hybrid system," Renewable Energy, vol. 28, no. 10, pp. 1491-1512, 2003.

[12] M. El Mokadem, C. Nichita, B. Dakyo, and W. Koczara, "Control strategy for a variable load supplied by a wind diesel system," Electromotion Journal, vol. 10, pp. 635-640, 2003.

[13] W. X. Shen, "State of available capacity estimation for leadacid batteries in electric vehicles using neural network," Energy Conversion and Management, vol. 48, no. 2, pp. 433-442, 2007.

[14] M. B. Camara, H. Gualous, F. Gustin, and A. Berthon, "Design and new control of DC/DC converters to share energy between supercapacitors and batteries in hybrid vehicles," IEEE Transactions on Vehicular Technology, vol. 57, no. 5, pp. 2721-2735, 2008.

[15] J. K. Kaldellis and D. Zafirakis, "Optimum energy storage techniques for the improvement of renewable energy sourcesbased electricity generation economic efficiency," Energy, vol. 32, no. 12, pp. 2295-2305, 2007.

[16] J. B. Copetti, E. Lorenzo, and F. Chenlo, "A general battery model for PV system simulation," Progress in Photovoltaics: Research and Applications, vol. 1, pp. 283-292, 1993.

[17] O. Gergaud, G. Robin, B. Multon, and H. Ben Ahmed, Energy Modeling of a Lead-Acid Battery within Hybrid Wind/Photovoltic Systems, EPE Toulouse, 2003.

[18] A. Sripakagorn and N. Limwuthigraijirat, "Experimental assessment of fuel cell/supercapacitor hybrid system for scooters," International Journal of Hydrogen Energy, vol. 34, no. 15, pp. 6036-6044, 2009.

[19] S. Zerkaoui, A. B. Mboup, D. Lefebvre, F. Guerin, J. Bosche, and A. El Hajjaji, "Sliding mode based control strategy for multi-sources renewable energy system," in Proceedings of the International Conference on Electric Power and Energy Conversion Systems (EPECS '09), November 2009. 
[20] J. A. Sabate, V. Vlatkovic, R. B. Ridley, F. C. Lee, and B. H. Cho, "Design considerations for high-voltage high-power fullbridge zerovoltage-switched PWM converter," in IEEE Applied Power Electronics Conference and Exposition, pp. 275-284, March 1990.

[21] S. J. Jeon and G. H. Cho, "A zero-voltage and zero-current switching full bridge DC-DC converter with transform isolation," IEEE Transactions on Power Electronics, vol. 16, no. 5, pp. 573-580, 2001.

[22] P. Z. Lin, C. M. Lin, C. F. Hsu, and T. T. Lee, “Type-2 fuzzy controller design using a sliding-mode approach for application to DC-DC converters," IEE Proceedings, Electric Power Applications, vol. 1526, pp. 1482-1488, 2005.

[23] J. Sun and H. Grotstollen, "Symbolic analysis methods for averaged modeling of switching power converters," IEEE Transactions on Power Electronics, vol. 12, no. 3, pp. 537-546, 1997.

[24] A. B. Mboup, F. Guerin, P. A. Ndiaye, and D. Lefebvre, "Control design for hybrid system based on dc/dc converters duty cycle value," COMPEL, vol. 30, no. 1, pp. 310-335, 2011.

[25] V. I. Utkin, "Variable structure systems with sliding modes," IEEE Transactions on Automatic Control, vol. 22, no. 2, pp. 212-222, 1977.

[26] A. Hijazi, M. Di Loreto, E. Bideaux, P. Venet, G. Clerc, and G. Rojat, "Sliding mode control of boost converter: application to energy storage system via supercapacitors," in Proceedings of the 13th European Conference on Power Electronics and Applications (EPE'09), September 2009.

[27] I. S. Kim, "Sliding mode controller for the single-phase gridconnected photovoltaic system," Applied Energy, vol. 83, no. 10, pp. 1101-1115, 2006.

[28] A. J. Forsyth and S. V. Mollov, "Modelling and control of DCDC converters," Power Engineering Journal, vol. 12, no. 5, pp. 229-236, 1998. 

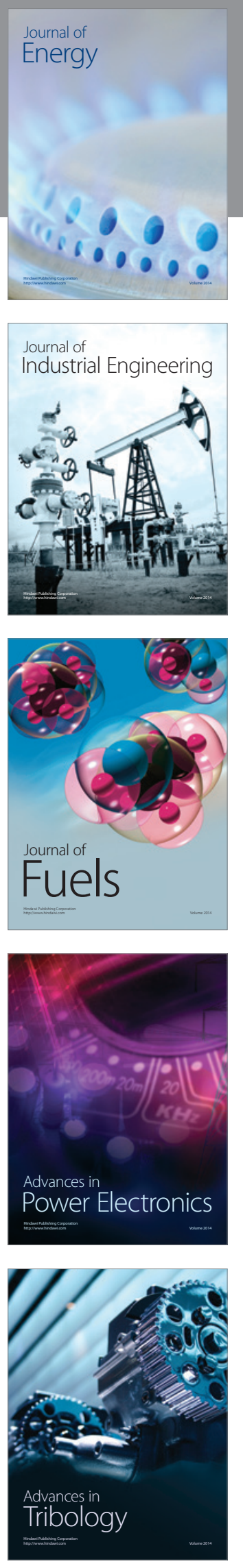
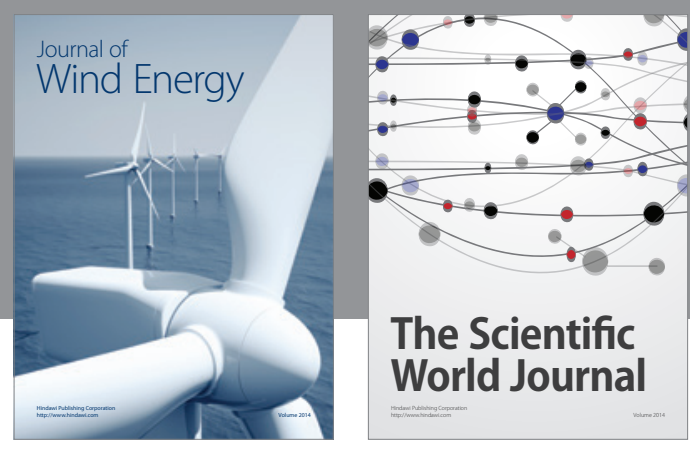

The Scientific World Journal

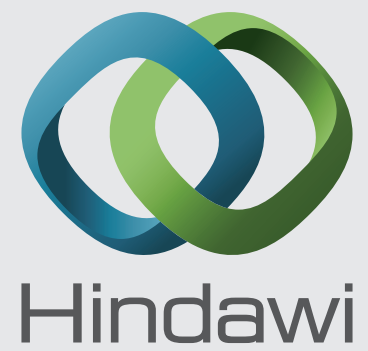

Submit your manuscripts at http://www.hindawi.com
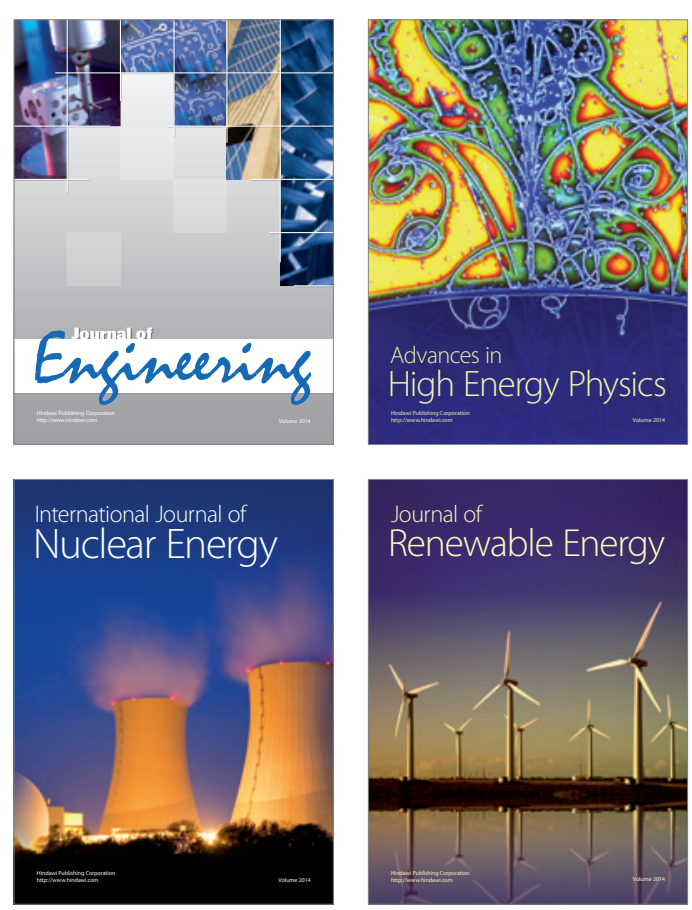

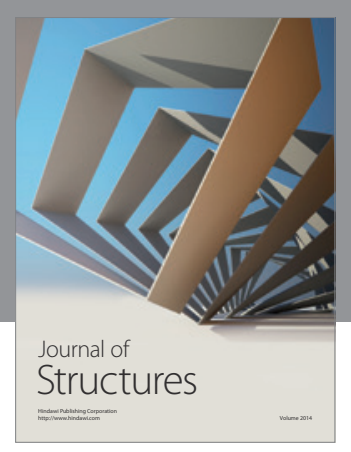

Rotating
Mechinery
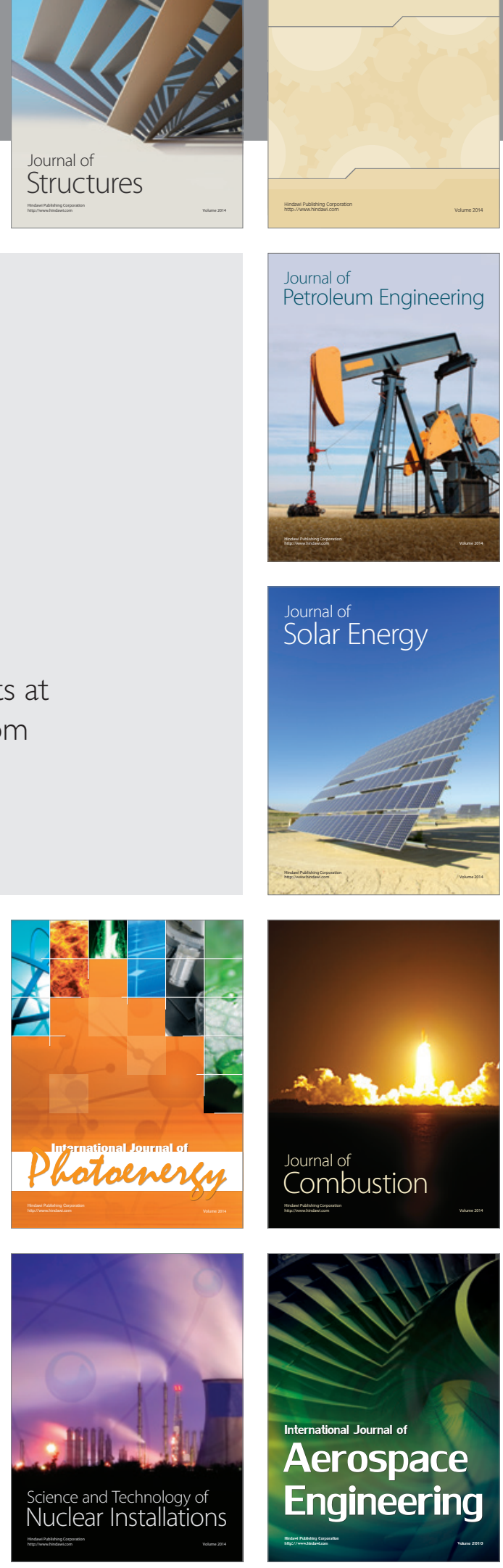